\title{
Current Limitations and Challenges with Lactic Acid Bacteria: A Review
}

\author{
Saeed A. Hayek, Salam A. Ibrahim* \\ Food \& Nutritional Sciences Program, North Carolina Agricultural and Technical State University, Greensboro, USA. \\ Email: sahayek@ncat.edu, ${ }^{*}$ ibrah001@ncat.edu
}

Received July $16^{\text {th }}, 2013$; revised August $16^{\text {th }}, 2013$; accepted August $25^{\text {th }}, 2013$

Copyright (C) 2013 Saeed A. Hayek, Salam A. Ibrahim. This is an open access article distributed under the Creative Commons Attribution License, which permits unrestricted use, distribution, and reproduction in any medium, provided the original work is properly cited.

\begin{abstract}
Lactic acid bacteria (LAB) play a critical role in food, agricultural, and clinical applications. The fast growing characteristics of LAB and their metabolic activity have been the key in most applications including food production, agricultural industry, and probiotics. However, the biochemical and biophysical environments have significant effect on the growth and metabolic activity of LAB. While the biochemical conditions are most likely established, controlling and optimizing of biochemical conditions have many limitations and challenges. In addition to selecting the right strain, desirable metabolic processes required optimizing and controlling the available nutrients including sugars, peptides, free amino acids, minerals, and vitamins in addition to buffering agents. Thus, much of research was conducted to understand the impact of available nutrients on the growth and metabolic activities of LAB. However, only a few nutritional parameters could be controlled at a time while holding other parameters constant. The nutritional parameters may also interact with each other resulting in faulty results. Characteristics of LAB such as fastidiousness in their nutritional requirements, ability to produce acid and antimicrobial compounds, and variations in the nutritional requirements among strains have added additional limitations and challenges in this regard. Thus, chemically defined media (CDM) were suggested to deal with different limitations and challenges. However, due to differences in growth conditions, results obtained in CDM may face some obstacles when it comes to industrial applications. Thus, this paper aimed to review the recent data in regard to the role of the nutritional requirements of LAB in optimizing and controlling metabolic activities and to discuss the associated limitations and challenges.
\end{abstract}

Keywords: Lactic Acid Bacteria; Metabolic Activity; Nutritional Requirements; Limitations; Challenges

\section{Introduction}

Lactic acid bacteria (LAB) are among the important groups of bacteria providing health benefits to human, animal, and plant $[1,2]$. Using LAB in food fermentation is one of the ancient known food preserving techniques. Properties such as nutritional, environmental, and adhesional adaptations have provided LAB with the ability to adapt and present in different environments ranging from food matrices such as dairy products, meats, vegetables, sourdough bread, and wine to human mucosal surfaces such as oral cavity, vagina, and gastrointestinal tract $[3,4]$. $\mathrm{LAB}$ are known for their fastidious nutritional requirements which may vary among species and even among strains [5-9]. Strains of LAB are also known as fast growing microorganisms that can explore different meta-

${ }^{*}$ Corresponding author. bolic activities. Metabolic activities are associated with production of many beneficial compounds such as organic acids and antimicrobial compounds, unique enzymes that can breakdown complex organic compounds into simple functional compounds $[4,9]$. Thus the fast growing characteristics and the metabolic activity are the keys of LAB benefits and applications.

Metabolic activities of LAB which are necessary for survival and growth are also important for any application. The primary metabolic activity in LAB is degradation of carbohydrates and related compounds to obtain mainly energy and carbon molecules [10,11]. However, proteinases and peptidases activities of LAB have gained much attention due to their importance in the accelerated maturation and enzyme modification of different food products especially cheese $[12,13]$. Other metabolic activities including lipolysis and degradation of complex 
compounds such as polyphenols and being of lavones have their important role in food industry and human health. However, the metabolic activities of LAB are not naturally optimized for maximal production rates of biotechnologically important compounds [10]. The growth and metabolic activities of LAB could be affected by both biochemical and biophysical environments. Biochemical environment is made available through culture media that are utilized for bacterial growth and referred to as nutrients or nutritional requirements. Depending upon the special nutritional requirements of particular LAB species a large variety of culture media have been developed with different purposes and uses. Coordination by growth factors and optimization of nutritional requirements could ensure that necessary enzymes and correct amount of each beneficial compounds are made at any given time $[10,11]$. Knowledge of factors affecting metabolic activities of LAB is important to optimize the activities and to achieve better controlled processes. Thus a large amount of research was established with regard to the relationship between LAB's nutritional requirements and metabolic activities. However, this type of research, dealing with controlling the metabolic activity, is facing many limitations and challenges. Because of the importance of controlling the metabolic activity of LAB, this paper thus aimed to review the recent research in the relationship between the metabolic activity and nutritional requirements of $\mathrm{LAB}$ and to highlight the associated limitations and challenges.

\section{Metabolic Activity of Lactic Acid Bacteria}

Metabolic activity of LAB has gained much focus in research and industry. The main metabolic activity of LAB is breaking down different carbohydrates and related compounds to obtain energy and carbon molecules $[10,11,14]$. Other metabolic activities such as breaking down proteins, lipids, and other compounds are also important for normal growth. Thus, the metabolic activities of LAB can include: carbohydrates metabolism, protein metabolism, lipids metabolism, and other metabolic activity.

\subsection{Carbohydrates Metabolism}

Carbohydrates are the main source of energy for bacterial growth. LAB metabolize carbohydrates into different useful compounds (mainly lactic acid) through a common process known as fermentation. Fermentation is a well documented process and thus only short summary of fermentation was included in this review. Fermentation is the metabolism of sugar in which energy is derived from partial oxidation of an organic compound using organic intermediates as electron donors and electron acceptors $[4,15]$. No outside electron acceptors are involved; no membrane or electron transport system is required; and all ATPs are produced by the substrate level of phosphorylation.

According to the mode of splitting carbon skeleton thus leading to different sets of end-products, three major pathways of hexoses fermentation were described to occur within LAB $[4,16]$. Based on fermentation pathways, LAB can be divided into two physiological groups: homo fermentative (e.g., Lactococcus lactis, L. delbrueckii, and L. casei) and heterofermentative (e.g., L. amylovorus, $L$. reuteri, and $L$. manihotivorans) $[4,17]$. Homofermentative $\mathrm{LAB}$ metabolize one molecule of hexose sugars such as glucose to two molecules of lactic acid and two molecules of ATP resulting in more than $85 \%$ lactic acid from one molecule of glucose $[4,15]$. Hetero fermentative LAB produce only $50 \%$ lactic acid fermenting one molecule of glucose to one molecule of lactic acid, one molecule of ethanol/acetate, one molecule of $\mathrm{CO}_{2}$, and only one molecule of ATP [15]. The ratio of acetate/ethanol depends on the oxidation reduction potential of the system. The difference in acid production and change in $\mathrm{pH}$ could be used as a basis for differentiation of these two groups of LAB. With regard to disaccharides and oligosaccharides, they are taken up with the help of specific permeases then will be split inside the cell into monosaccharides to be phosphorylated. For example, lactose is taken up by a specific permease and is split, in most lactobacilli, by $\beta$-galactosidase to form monosaccaride.

\subsection{Protein Metabolism}

LAB have gained much attention due to their proteolytic activities, which are of especial importance in the accelerated maturation and enzyme modification of different food products such as cheese. Proteolysis is the process in which proteins are broken down by proteinases and peptidases into polypeptides, amino acids, and peptides $[13,18]$. Proteinases and peptidases can be found as extracellular and secreted as free enzymes outside the cell or intracellular inside the cell. The proteolytic systems of LAB are important as a means of making protein, peptide, and amino acids available for bacterial growth, but these systems can also formthe rheological and organoleptic properties of fermented foods $[18,19]$. Proteolysis has been particularly well documented in relation to the growth of lactobacilli and lactococci in milk, where they are largely responsible for flavor development during cheese production $[18,19]$. Proteinase also helps to reduce the allergic properties of milk and milk products for infants which can lead to a severe nutritional problem of protein-energy deficiency [20]. Of cheese making LAB strains, L. helveticus and Lactococcuslactis have been studied in greatest detail [13].

Many peptidases (e.g. Aminopeptidase C, Aminopeptidase N, Aminopeptidase A, X-prolyldipeptidylamin- 
opeptidase, Prolidase) have been identified and classified. These peptidase have exhibited wide differences among LAB species and even strains [13]. LAB proteolytic systems are comprised of three components: 1) cell-wall bound proteinase that initiates the degradation of extracellular protein into oligopeptides, 2) peptidetransporters that take up the peptides into the cell, and 3) intracellular peptidases that degrade peptides into shorter peptides and amino acids [19]. Amino acids can be further converted into various flavor compounds, such as aldehydes, alcohols and esters [21]. The advantage of direct transport of peptides into the cell prior to hydrolysis lies in the reduction of the amount of metabolic energy used for amino acid uptake. Amino acid catabolism by LAB is also believed to have an important role in the ability to obtain energy in nutrient limited environments. In addition, proteinase, oligopeptide transport system, and peptidases were shown to be distributed unevenly among LAB strains, which was probably the result of the presence or absence of plasmids that encode them [19].

Several reviews have described the proteolytic system of LAB with respect to LAB's biochemical and genetic aspects $[12,13,20,22]$. In addition, nowadays more than 1000 complete genome sequences for bacteria have been annotated including $45 \mathrm{LAB}$ strains [3]. This work has made possible thorough comparative analysis of LAB proteolytic systems at a genome scale. With the current knowledge of proteolytic processes and genome sequences for $\mathrm{LAB}$, we are able to genetically engineer starter $\mathrm{LAB}$ and obtain the desired proteolytic activity.

\subsection{Lipid Metabolism}

Lipid metabolism is the break down of lipid by lipases into fatty acids and glycerol. LAB strains have either intracellular or extracellular lipases [23,24]. In addition, $\mathrm{LAB}$ strains perform unique fatty acid transformation reactions including is omerization, hydration, dehydration, and saturation [25]. These functions can be used in food industry and probiotics. For example, lipolyses of milk fat by LAB constitute the main biochemical changes in cheese flavor development $[23,24]$. However, not all LAB strains can metabolize lipids. Meyers and others (1996) screened over 100 different LAB strains for lipase production and identify only 29 lipase-producing strains.

Lipase activity of LAB has shown to provide different health benefits to the host. Lipases are useful in the preparation of dietetic formulations for infants, geriatrics, and convalescents $[25,26]$. Evidence from mice, preclinical and clinical trials has revealed that lactobacilli can also break down cholesterol into serum lipids [26]. The hypolipemic effect of Lactobacillus could be due to a lower intestinal absorption of lipids or a higher lipid catabolism [26]. Taranto and others [26] have suggested that the hypocholesterolemic effect of $L$. reuteri could be related to the hydrolase activity of bile salts by the cells. In addition, LAB can produce conjugated linoleic acid (CLA) from linoleic acid [25]. Conjugated fatty acids such as CLA have attracted much attention as a novel type of biologically beneficial functional lipid. Castor oil, which is rich in the triacylglycerol form of ricinoleic acid, was also found to act as a substrate for CLA production by $\mathrm{LAB}$ with the aid of lipase-catalyzed triacylglycerol hydrolysis. Conjugated trienoic fatty acids can be saturated by LAB to trans-10, cis-15-18:2 and cis-6, trans10-18:2, respectively [25]. Thus, some isomers of CLA reduce carcinogenesis, atherosclerosis, and body fat.

\subsection{Other Metabolic Activities}

LAB strains express several other metabolic activities that are major contributors to sensory changes in fermented foods such as flavor, astringency, and color by breaking down different organic compounds in the food matrix [2]. These enzymes also play an important role in the probiotic characteristics of LAB contributing to a variety of health benefits in humans, animals, and plants [1]. LAB metabolize different simple and complex functional compounds such as terpenoids, carotenoids, sterols, polyphenols, and isoflavones [2,11,27]. In general these complex functional compounds are known for their health benefits but they are unavailable for gut absorption. The metabolic process in food fermentation or in the gut will degrade these compounds to smaller metabolites that can be absorbed and benefit the host organism [27].

Diacetyl is produced during conversion of citric acid in milk to pyruvate and pyruvate is converted to $\alpha$-actolactateand then to the precursor for diacetyl. Most LAB strains can decarboxylate $\alpha$-acetolactate by $\alpha$-acetolactate decarboxylase to the metabolic end-product acetoin and aromatic whereas some LAB strains do not contain the responsible enzyme, resulting in accumulation of $\alpha$-acetolactate and high production of diacetyl in dairy products [11]. Acetaldehyde is a major contributor to flavor in dairy products, and it is produced mainly by LAB. In addition, LAB can be used to inhibit the growth of harmful microorganisms by producing different antimicrobial compounds including bacteriocin, hydrogen proxide, carbon dioxide, and diactyle in addition to the rapid production of lactic acid [28]. Wine LAB play a preeminent role in the production of grape wines where their growth and metabolismmay positively or negatively affect wine quality [29]. LAB may also metabolize diacetyl and acetaldehyde during malolactic fermentation in wine and the remove Ochratoxin A from wines [30].

LAB can be also used for the production of exopolysaccharides (EPS) during fermentation to ensure properrheology, texture and mouth feel of fermented food [31]. 
EPS could be an alternative low calories and low cost ingredient that can be used to produce smooth and creamy yogurt instead of fat, protein, sugars, or stabilizer [31]. However the production of EPS from LAB can be effected by oxygen, $\mathrm{pH}$, temperature, and medium constituents, such as orotic acid and the carbon source [32].

\section{Biochemical Environment of Lactic Acid Bacteria}

Bacteria, in general, require an appropriate biochemical and biophysical environment to grow and express normal metabolic activities. Biophysical environmental factors including temperature, $\mathrm{pH}$, water activity, redox potential, and the presence of inhibitory compounds produce a wide range of variations among LAB strains [33]. The biochemical environment conditions are made available through nutrients in the culture media. LAB are known as fastidious micro organisms that cannot grow on simple mineral media supplemented only with a carbon source [34]. In addition to carbohydrates (carbon source), culture media of LAB are usually supplemented with various free amino acids, peptides, nucleic acid derivatives, fatty acids esters, minerals, vitamins, and buffering agents $[6,17]$.

Nutritional requirements are classified as essential, stimulatory, and unessential [7,35]. Essential nutrients have an absolute effect on the growth of bacteria and no growth can be detected in the absence of these nutrients. Stimulatory nutrients enhance bacteria growth and lower growth rate is found in the absence of these nutrients. Unessential nutrients have no effect on the growth of bacteria, neither enhancement nor inhibition. However, nutrients, whether they are essential, stimulatory, or unessential, play an important role in optimizing and controlling the metabolic activities. The use of known starter cultures with technological and functional properties was suggested to optimise fermentation conditions and improve the quality of fermented foods [36-38]. According to Leroy and others [36], functional starter cultures could improve microbial safety or represent organoleptic, technological, and nutritional characteristics of food or health advantages. Due to the important role of nutrients in the metabolic activities of LAB, nutritional requirements of LAB are given more attention in this review.

\subsection{Carbohydrates}

Carbohydrates are the main source of carbon and energy that form essential components in LAB media for normal growth and functionality [4,39]. However, carbon and energy can be also obtained from protein, amino acids, and glycerol. Most sugars could be utilized by LAB assources of carbon and energy but glucose is commonly preferred by large number of LAB strains [40]. However,
LAB strains had shown preferences among different sugars and thus LAB strains vary in their abilities to ferment different sugars which could affect their growth and functionality. For example, L. acidophilus has showed better growth when glucose was replaced by maltose, salicin, raffinose or melibiose. L. fermentum showed the best growth with maltoseand was significantly different fromthat obtained with starch, glucose, and melibiose [41]. S. thermophilus normally requires lactose not glucose. Oenococcusoeni R1034, O. oeni R1054, L. buchneri CUC-3, and L. hilgardii MHP from wine showed highest maximum specific growth yield and growth rates growing in media with ribose compared to that in glucose or fructose [42]. L. hilgardii MHP did not grow in CDM containing glucose or fructose as carbohydrate source after three subcultures [42]. Thus the growth and metabolic activities of LAB could be affected by the available carbon sources [43].

Differences in sugar requirements among LAB strains can be used for enumeration, selection, and identification. MRS supplemented with fructose was suitable for enumeration of L. bulgaricus and MRS supplemented with maltose was suitable for differentiation between $L$. acidophilus and L. paracasei [44]. MRS supplemented with maltose was found suitable to enumerate L. acidophilus and bifidobacteria [45]. Lactulose a disaccharide derivative of lactose, was found suitable to support a high level of growth for different L. ruminis strains [39]. L. casei has showed the highest specific phytate-degrading activity when the glucose concentration in the growth medium was of $2 \%$, whereas an increase in twice the glucose concentration dramatically decreased $L$. casei enzymatic activity [46]. Thus, even though glucose is commonly used in LAB media, LAB species and even strains have shown preferences among sugars for optimum growth and metabolic activity. Concentration of sugars may also influence the growth and functionality of LAB.

\subsection{Amino Acids and Peptides}

LAB have multiple amino acids and peptides requirements to meet their demand of complex nitrogen [13]. It is believed that evolution on complex rich media resulted in selection of specific auxotrophies that are very much related to their preferred environmental conditions and differ among LAB species $[4,13]$. Amino acids and peptides can be obtained through the action of proteases or proteolysis. In these actions, peptides are being metabolized to free amino acids and other subsequent utilization compounds. According to the differences in peptides requirements among $\mathrm{LAB}$ strains, peptides can be either essential growth factors or stimulatory factors, also some strains can grow without them [7,47]. Growth of LAB depends on those amino acids from organic nitrogen sources since LAB have very limited capacity to synthe- 
size amino acids from inorganic nitrogen source [4]. Amino acid requirements of $\mathrm{LAB}$ is strain dependent with wide range of differences among species and stains [7,47]. For example, only 3 amino acids are required for L. plantarum while $L$. acidophilus require 14 amino acids [47]. Letort and Juillard (2001) have reported that five out of six different $S$. thermophilus strains exhibited no absolute amino acid requirement and proline or histamine are essential for only one strain. Some amino acids (Methionone, Cysteine, Leucine, and Valine) were found stimulatory for all six S. thermophilus strains and other amino acids (Asparagine, Alanine Isoleucine, Glycine, Serine and Threonine) were found unessential [7]. An investigation of amino acid requirements for several species of lactobacilli demonstrated that $L$. acidophilus, $L$. delbrueckii subsp. bulgaricus and $L$. delbrueckii subsp. lactis exhibit wider requirements than $L$. plantarum, $L$. pentosusand $L$. curvatus [34,48]. Strains belong to $L$. plantarum, will require nutritionally simpler medium [49]. Therefore, defects in amino acid biosynthetic capacity in L. plantarum, with big genome size, are less than those in L. johnsonii, with small genome size [50].

Amino acids and peptides can be derived from different organic nitrogen sources such as papain-digested skim milk, yeast extract, tryptone (trypsine-treated casein), soy peptones, peptones of animal origin, beef extract, corn steep liquor, liver extracts, whey protein hydrolysates, etc. [34,51,52]. However; peptone, beef extract, and yeast extractare more commonly used and seems to be convenient for normal growth of LAB [53]. These nitrogen sources are known to contain a wide range of amino acids and peptides that can satisfy requirements of most LAB strains. Thus replacing yeast extract with beefextract, casitone or gluten as other sources of nitrogen did not increase growth compared with yeast extract alone [41]. Replacing half the amount of yeast extract with either beef extract or malt extract was found to reduce the biomass and bacteriocin production from L. sakei CCUG 42687 [54]. Replacing tryptone with bacteriological peptone or soytone was good for growth and bacteriocin production, while a fish hydrolysate shows reduction in the growth of L. sakei [33]. When peptone, beef extract, and yeast extract were replaced in food grade medium by yeast peptone, which is made from bakery yeast, $L$. plantarum was able to grew whereas other lactobacilli strains such as L.acidophilus, $L$. delbrueckii subsp. bulgaricus, and $L$. delbrueckii subsp. lactis could notgrew [49]. Thus replacing beef extract, yeast extract, and peptone with other nitrogen sources or even with each other may negatively affect the growth.

In addition, yeast extract, beef extract, and peptone are not only a nitrogen sources; they are also sources of carbon, minerals, and vitamins [41]. Thus, complementation ofnitrogen sources with a vitamin or amino acidsolution did not have any positive effect on growth [41]. High concentration of yeast extract ( $\mathrm{YE}>12 \mathrm{~g} / \mathrm{L}$ ) can also depress LAB growth in unbuffered medium [55]. The use of bacteriological peptone or soytone in LAB growth media was found to better serve the growth and bacteriocin production compared totryptone or fish hydrolysate [33]. The use of yeast extract and bacteriological peptone in high concentrations resulted in a reduced growth of LAB strains [33]. High concentrations of tryptone (TR > $35 \mathrm{~g} / \mathrm{L}$ ) was found to depress the growth [55]. An increase in tryptone from $0.25 \mathrm{~g} / \mathrm{L}$ to $5 \mathrm{~g} / \mathrm{L}$ tryptone, keeping other factors constant, showed no increase in growth [33]. In addition, the increase in peptide concentration for those amino acids composition is different from that required for balanced growth may limit the uptake of essential peptides and amino acids and resulted in growth limitation [33]. Therefore, it is of crucial importance to include balanced amounts of yeast extract, beef extract, and peptone in LAB culture media to ensure suitable level of growth and better functionality.

\subsection{Fatty Acids}

Fatty acidsarecarboxylic acids $(\mathrm{COOH})$ with short, medium, or long chain of carbon atoms that are either saturated or unsaturated. Fatty acids typically bind to other compounds such as glycerol, sugars, or phosphate to form lipids. Lipids are components of cell structures (phospholipids) and energy stores (triglycerides). Fatty acids have many well defined biological functions [56]; however, there are limited data on the roles of fatty acids and fats as growth factors for LAB [56-58]. Most investigations about the relationship between fatty acids and growth of microorganisms including LAB have demonstrated the antimicrobial effects of fatty acids [56,59]. Thus fatty acids in general can inhibit the growth of microorganisms, but small amounts such as $0.1 \%$ of fat may tend to stimulate bacterial growth [59].

Fatty acids with longer carbon chains usually exhibit stronger inhibitory effects than those with shorter chains, plus unsaturated fatty acids tend to be more inhibitory than saturated ones [56-58]. Gram positive bacteria such as $\mathrm{LAB}$ are more susceptible to long chain fatty acids than Gram negative bacteria [56]. The inhibitory effect of fatty acids is more $\mathrm{pH}$ dependent [60]. In addition, even though the antimicrobial effect of fatty acids has been well studied, the exact mechanism by which fatty acids inhibit bacterial growth has not been well defined $[56,60]$.

\subsection{Vitamins}

Vitamin requirements of $\mathrm{LAB}$ can be classified into three categories: essential vitamins that cause $67 \%$ reduction in growth when omitted, stimulatory vitamins that cause 
between 34 and $66 \%$ reduction in growth when omitted, and non-essential vitamins that cause less than $67 \%$ reduction in growth when omitted. Pantothenic, riboflavin, and nicotinic acid are essential for most LAB strains $[7,35,61]$. When riboflavin was omitted from the minimal medium of $L$. plantarum, a severe inhibition of growth was observed [61]. Thiamine is required for the growth of lactobacilli on arabinose, ribose, and gluconate acting as a cofactor of phosphoketolase, an enzyme involved in pentose phosphate pathway. Biotin can be a stimulatory factor for the growth of some LAB strains or an essential factor for other strains [8]. Ascorbic acid has no effect on the growth of some LAB strains [35] but it is essential growth factor for other strains $[33,61]$. Thus, it is evident that vitamin requirements of LAB represent many differences among strains, and some vitamins can replace each other; however, individual strains required from one to four vitamins for normal growth.

\subsection{Minerals}

Minerals play an essential role in microbial growth in general and have a special effect on bacterial enzymatic activity [35]. Some LAB species such as Leuconostocmesenteroides cannot grow in the absence of metal ions, indicating the absolute requirement for metal ions [35]. Essential metal ions serve bacteria in a number of functions: 1) as activators or cofactors of a variety of enzymes, 2) in membrane transport, and 3) as components of molecules or structural complexes [6]. It has been reported that at least trace amounts of manganese $\left(\mathrm{Mn}^{2+}\right)$ is essential for the growth and metabolic activity of most organisms including LAB. $\mathrm{Mn}^{2+}$ has biological effects on the structure and activation of numerous enzymes such as glutamine synthetase, RNA polymerase, lactate dehydrogenase, and alkaline phosphatase [62]. Magnesium $\left(\mathrm{Mg}^{2+}\right)$ is another essential element for the growth and metabolic activities of LAB. $\mathrm{Mg}^{2+}$ stimulated the growth of $\mathrm{LAB}$ and improved LAB survival. It was shown that $\mathrm{Mg}^{2+}$ is the only essential oligoelement for the growth of L. delbrueckii ssp. Lactis [34]. $\mathrm{Mg}^{2+}$ was also found to be an essential metal ion for the growth of $S$. thermophilus [7]. The addition of $\mathrm{Mg}^{2+}$ and $\mathrm{Mn}^{2+}$ to minimal medium of L. plantarum assured its growth [61].

$\mathrm{Mn}^{2+}$ is stimulatory for Leuconostoc mesenteroides whereas $\mathrm{Mg}^{2+}, \mathrm{Ca}^{2+}, \mathrm{Fe}^{2+}, \mathrm{Zn}^{2+}, \mathrm{Co}^{2+}$, and $\mathrm{Cu}^{2+}$ are unessential [35]. $\mathrm{Ca}^{2+}$ was found to stimulate the growth of $S$. thermophilus but was not an essential factor [7]. $\mathrm{Mg}^{2+}$, $\mathrm{Mn}^{2+}, \mathrm{Na}^{+}, \mathrm{K}^{+}$, and $\mathrm{Cl}^{-}$were found to be essential components in minimal growth media for L. plantarum [61]. Removing $\mathrm{Fe}^{2+}, \mathrm{Zn}^{2+}, \mathrm{Co}^{2+}$, and $\mathrm{Cu}^{2+}$ from chemically defined medium did not affect the growth of $S$. thermophilus [7]. Thus, LAB in general required $\mathrm{Mn}^{2+}, \mathrm{Mg}^{2+}$, $\mathrm{Ca}^{2+}, \mathrm{Fe}^{2+}, \mathrm{K}^{+}$, and $\mathrm{Na}^{+}$as essential or stimulatory factors for nutrient transportation and enzymatic activity.
Several studies have focused on the relationship between metal ions and enzymatic activity of LAB [35, 63-66]. The addition of $10 \mathrm{mM}$ of $\mathrm{Mn}^{2+}$ has caused significant enhancement (150\% to $230 \%)$ in $\beta$-glucosidase activity while $10 \mathrm{mM}$ of $\mathrm{Zn}^{2+}$ or $\mathrm{Cu}^{2+}$ has caused up to a $90 \%$ reduction in $\beta$-glucosidase [66]. The enzymatic activity of acid phosphatase can be enhanced by both $\mathrm{Ca}^{2+}$ and $\mathrm{Mg}^{2+}$ with a higher effect due to $\mathrm{Ca}^{2+}$ [67]. The activity of acid phosphatase was enhanced in the presence of some ions such as $\mathrm{Ca}^{2+}, \mathrm{Mg}^{2+}, \mathrm{Mg}^{+2}$, and $\mathrm{Cu}^{+2}$ but diminished by $\mathrm{Co}^{+2}$ and inhibited by $\mathrm{Fe}^{2+}$ [67-69]. The presence of inorganic phosphate (Pi) in the form of dipotassium phosphate and sodium phytate in MRS markedly reduced the phosphatases activity [69]. Therefore, heavy metals such as $\mathrm{Hg}^{2+}, \mathrm{Cu}^{2+}, \mathrm{Ni}^{2+}, \mathrm{Zn}^{2+}$, and $\mathrm{Co}^{2+}$ could inhibit the enzymatic activity whereas $\mathrm{Mn}^{2+}$ and $\mathrm{Mg}^{2+}$ are known to enhance the enzymatic activity [70]. Therefore, metal ions play an important role in the growth and metabolic activity of LAB and could be further used to optimize and control the enzymatic activity.

\subsection{Tweens}

Tweens are polysorbates which are a class of emulsifiers used in pharmaceuticals and food preparation. Series of Tweens are available including Tween 20 (Polyoxyethylene (20) sorbitanmonolaurate), Tween 40 (Polyoxyethylene (20) sorbitanmonopalmitate), Tween 60 (Polyoxyethylene (20) sorbitanmonostearate), and Tween 80 (Polyoxyethylene (20) sorbitanmonooleate). However, not all Tweens are important for bacterial growth, Tweens such as Tween 80 and 85 that contain oleic acid are known to enhance the growth of LAB and many other bacterial groups $[59,71,72]$. Oleic acid is also anessential growth factor for a variety of LAB strains and was therefore suspected as the active materialin LAB culture media [59]. Supplementing LAB media with Tween 80 incorporates oleic acid into the cell membrane and further convert oleic acid into cyclopropane fatty acids, characteristic fatty acids especially in lactobacilli [59]. It is believed that the role of cyclopropane fatty acids is to increase fluidity of LAB membranes like polyunsaturated fatty acids and to protect LAB from different environmental conditions such as low $\mathrm{pH}$, deleterious effects of oxygen, and extreme temperatures [72,73].

Tween 80 assists in nutrient uptake and is incorporated inphospholipids from the cytoplasmic membrane, improving membrane permeability. Tween 80 has a significant effect on recovery ability [72], bile tolerance [74,75], and metabolic activity [33] of LAB strains. Tween 80 was also found to enhance the production of enterocin 1146 and lactocin $\mathrm{D}$ that are produced by LAB [76]. The stimulatory effect of Tween 80 on growth at $\leq 1 \mathrm{~mL} / \mathrm{L}$ was confirmed and the increase of Tween 80 concentration showed a negative effect on growth [33]. In addition, 
lactic acid production was found to increase in proportion to increasing Tween 80 concentration up to slightly more than $1.5 \mathrm{~mL} / \mathrm{L}$, then decreased gradually beyond these ranges [51]. In general, reducing the amount of Tween 80 below $1 \mathrm{~mL} / \mathrm{L}$ will most commonly result in diminished in LAB growth.

\subsection{Buffering Agents}

LAB produce acid (mainly lactic acid) during growth, which lowers the $\mathrm{pH}$ value of the media and thus slows down or inhibits the growth. Thus it is important to include buffering agents in the culture media. In most LAB genera, $\mathrm{pH} 4.4$ could inhibit the growth or significantly slow growth rate. Most Lactobacillus strains grow at optimum $\mathrm{pH}$ between 5 to 6 , but they can also grow at a relatively low pH (4.4) [4]. Therefore, including buffering agents in the culture media is important to maintain the appropriate $\mathrm{pH}$ for LAB growth. Sodium acetate, trisodium citrate, and Di-sodium-glycerophosphate are essential buffering agents that commonly used in LAB media such as MRS and M17. Omission of sodium acetate from the growth medium caused lower lactobacilli growth due to reduction of medium $\mathrm{pH}$ [49]. Other components used in MRS with buffering activity include disodium phosphate $\left(\mathrm{Na}_{2} \mathrm{HPO}_{4}\right)$, ammonium citrate $\left(\mathrm{NH}_{4} \mathrm{C}_{6} \mathrm{H}_{5} \mathrm{O}_{7}\right)$, and dipotassium phosphate $\left(\mathrm{K}_{2} \mathrm{HPO}_{4}\right)$.

The $\mathrm{pH}$ value of the media has a major affect on the metabolic activity of LAB. For example, several reports have shown the maximum phosphatases activity at $\mathrm{pH} 5$ [46,69,77,78]. Enzymatic activities of L. acidophilus have an optimum activity level at $\mathrm{pH}$ 5. Chan and $\mathrm{Li}$ [79] reported an initial $\mathrm{pH}$ of 6.5 to maximize $\alpha$-glucosidase production of L. acidophilus, while Mahajan and others [80] have found an optimum $\mathrm{pH}$ of 6.0 for the production of cell wall-bound $\alpha$-glucosidases. In addition, $\alpha$-glucosidase remained highly stable within $\mathrm{pH}$ range $6.0-7.0$ during $24 \mathrm{~h}$ of storage at $30^{\circ} \mathrm{C} \pm 0.5^{\circ} \mathrm{C}$, and activity was found to increase with temperature with maximum activity at $50^{\circ} \mathrm{C}[80]$. Based on the $\mathrm{pH}$ optima, most $\mathrm{LAB}$ strains have high acid phosphatases activity in $\mathrm{pH}$ ranges between $\mathrm{pH} 4$ - 6 with an optimum $\mathrm{pH}$ of $5[46,67,69,81]$. Thus $\mathrm{pH}$ is one of the important aspects need to be considered for optimum growth and better functionality.

\section{Lactic Acid Bacteria: Limitations and Challenges}

LAB have gained increased attentions in research and industry during the last few decades due to the increased applications of LAB and especially with regard to probiotics. The growth characteristics and metabolic activity of LAB have significant impact on the applications. LAB have fastidious nutritional requirements which required complex nutritional media for normal growth and meta- bolic activity. The fastidious characteristics of LAB may impact the study of the nutritional requirements and metabolic capacity. Fastidious nutritional requirements may also limit the ability to optimize and control the metabolic activities of LAB. Limitations and challenges with regard to LAB use and applications may apply to different areas including formation of cultivation media, optimizing and controlling metabolic activities, studying the nutritional requirements, and decrease in viability and functionality during storage.

\subsection{Formation of Cultivation Media}

Several culture media have been developed to serve the growth and metabolic activities of LAB. The composition of the culture media has number of factors claimed to affect the growth and functionality of LAB. However, existing media did not satisfy all purposes especially those related to industrial and health applications. For example, existing media such as MRS and M17 are expensive, require specific preparation steps, and need a long incubation time. Cost is considered to be the single most important issue with regard to the industrial use of LAB media. Cost is primarily due to the expensive nitrogen sources such as beef extract, yeast extract, and peptone [53,82-84]. As a result, several studies were carried out to lower the cost of LAB culturing media using low cost materials such as food byproducts, agriculture products, and agriculture wastes. With this aim whey and buttermilk [85], de-lipidated egg yolk and yeast autolysate [83], papain-hydrolysed whey [86], cassava bagasse and sugarcane bagasse [87], ram horn [88], and many other low cost ingredients were investigated. Many of these materials were able to show a significant improvement in LAB growth and functionality compared to MRS when enhanced with little nutrients. In our laboratory, sweet potato, an abundant agricultural product in the state of North Carolina, was investigated to replace the expensive nitrogen sources in LAB cultivation media [65]. Our findings indicated that sweet potato could partially replace the expensive ingredient in LAB media and thus could form an alternative low cost medium.

In addition to cost, media composition includes number of factors that might effect the growth and functionality of LAB. These limitations include the availability of certain essential molecules that are required for cell metabolism, the production of organic acids that cause a drop in media $\mathrm{pH}$ resulting in antimicrobial effects, lack of nutrients during exponential growth, lack of essential minerals such as $\mathrm{Fe}^{2+}$ and $\mathrm{Ca}^{2+}$ that are required by some LAB strains, and lack of different carbon sources that are required or preferred by some LAB strains $[44,83,85,89]$. These limitations are due to the fact that $\mathrm{LAB}$ strains have a wide range of variations in their growth requirements and that cause much of complexity forming gen- 
eral growth media for LAB. The fastidious characteristics of LAB, the ability of LAB strains to produce acid and antimicrobial compounds, and the variations in nutritional requirements among $\mathrm{LAB}$ strains have added additional limitations and challenges with regard to developing general growth media. In addition, metabolites that are produced by some LAB strains may inhibit the growth of other strains or even the same strain such that the case of bacteriocin production. On the other hand, low nutrient concentrations may cause fast depletion in the essential nutrient which may negatively affect growth [89] whereas high nutrient concentration such as salts could also negatively affect growth or could be insoluble in water $[33,35,55,63]$. Therefore, several research studies focused on finding alternative ways to lower the cost of the available media $[52,83,85]$ or focused on minimizing negative characteristics of the available media $[44,45,51]$, whereas others worked on enhancing LAB functionality by optimizing the media composition [63, $90,91]$. However, forming a cultivation media and optimizing the nutrients in the cultivation media of LAB in order to maximize the functionality and metabolic activity of LAB still a valid concern that need to be given more attention in future research.

\subsection{Studying the Nutritional Requirements}

Complex media cannot be used to study the nutritional requirements or the metabolic engineering and metabolic activity of LAB $[7,33,61]$. Thus several CDMs were developed for different research purposes including investigations of the nutritional requirements, identification of specific characteristics, and isolation of auxotrophic mutants [34]. With this aim, a CDM to support a high cell density of lactococci, enterococci, and streptococci [92], a minimal CDM for exponential growth of $S$. thermophilus [7], a food grade media for culturing L. plantarum [49], a minimal CDM medium for the growth of L. plantarum [61], a CDM for the growth of Leuconostoc mesenteroides [35], a selective medium for isolation of lactobacilli from feces [93], CDM for wine Oenococcus, Lactobacillus, and Pediococcus [42], an optimized media for the growth of L. sakei [33], and several other CDMs were developed. However, establishing CDM requires extensive knowledge ofthe nutritional requirements of the corresponding species or strain under the study [7].

To determine the nutritional requirements of LAB usually each component of the complete media is omitted at a time. During single omission experiments components, for which the biosynthetic capability is present, can be omitted without complete abolishment of growth [61]. In addition, studying the nutritional requirements of $\mathrm{LAB}$ may require the culture to be subcultivated for few times in the new media or new formula to obtain the desirable growth. For example, eight subcultivations were required to obtain a stable growth response for cultivations of $O$. oeni R1034 and L. hilgardii MHP from wine in a medium deficient in folic acid [94]. Subcultivations may result in adapting the new media or nutritional environment which may result in a faulty conclusion. The smallest genome size species have the highest adaptation to nutritional rich environments and the largest genome size species have more versatile habitats [95]. Adaptation phenomenon may lead to omit a component that has a stimulatory or even essential role on the growth to be considered as unessential.

Studying the vitamin requirements for $\mathrm{LAB}$ growth are complicated since vitamin requirements of LAB represent many differences among strains and some vitamins can replace each other. In general an individual strain required from one to four vitamins for normal growth. The vitamin composition was a critical point in the formulation of CDM to support growth of two O. oeni and two Lactobacillus spp. strains from wine since several growth attempts in media with a reduced number of vitamins was unsuccessful [42]. Based on metabolic network of L. plantarum, it was predicted that folate, biotin, and pyridoxamine are essential for growth. Wegkampand others [61] showed that the removal of these vitamins did not abolish the growth of $L$. plantarum and thus Wegkamp and colleagues have suggested that growth in the absence of biotin, pyridoxamine, and folate could be due to the present of trace amounts of these vitamins in the medium or alternative reactions occur that do not require these vitamins. These results could bring another challenge in identifying the required vitamins to the respond species or strain.

The growth of microorganisms including LAB required trace amounts of different minerals [35,62]. Studying the mineral requirements of $\mathrm{LAB}$ usually observed in CDM by omitting one metal ion in a time $[35,42]$. However, comprehensive studies on the mineral requirements for bacterial growth and metabolic activity are also complicated and challenging due to several seasons including that metals can replace each other, some metals adsorb others, some metals interact differently in the presence of others, and many organic substances can combine with metals and render them unavailable for growth. In addition, when omitting individual metals to determine their essential role for growth it is possible that small contaminations from other medium compounds or from the glassware may lead to faulty results [94]. Thus comprehensive studies and examination on the essential nutritional requirements of $\mathrm{LAB}$ have several limitations including the fastidious nutritional requirements of LAB; some nutrients may replace others; some nutrient could be required only in the present of other nutrients; the ability of LAB to adapt to different nutritional environments; and the wide range of differences in the nutri- 
tional requirements among LAB strains.

\subsection{Controlling and Optimizing the Metabolic Activity}

For metabolic investigations of LAB it is desirable to have a CDM that can provide reproducibility of chemical composition; avoid unnecessary nutrients and adjust nutrients levels; meet the experimentally determined nutritional requirements of different strains; and support growth at a reasonable rate [35]. On the other hand, since LAB are not naturally optimized for maximal metabolic activity, the enzymatic activity of LAB need to be optimized and maximized towards the desired level of production and the desired end products. Thus many concerns were given to the selection, enhancement, stability, or optimization of different enzymes produced by LAB towards the desired level of activity. Enzymatic activity of LAB is natural process as a result of normal growth and thus the composition of the growth media could play a critical role in the enzymatic activity of LAB.

Growth and metabolic activity of LAB are crucial for the production and quality of fermented foods and for probiotic functionality. Studies related to the growth and metabolic activity of LAB are usually conducted in laboratory media and laboratory environment while use and applications of LAB are conducted in food, feed, or fertilizers. Growth conditions in the laboratory may differ from those available in the industry. Thus it was suggested to study the growth and metabolism of wine LAB in their natural environment wine $[42,94]$. However, studies in wine may be most relevant from a practical viewpoint and these studies may suffer from reduced applicability to wines made from different grape varieties, in different regions or vintages. In addition, growth in wine tends to be very slow, mainly because of the combined inhibitory effects of ethanol and organic acids. On the other hand, during industrial fermentation, LAB may lead to the formation of compounds with negative organoleptic properties, such as $\beta$-D-glucans [96] and acetic acid [29], as well as the amino acid degradation products such ascitrulline, a precursor of carcinogenic ethyl carbamate $[97,98]$ and biogenic amines. Therefore, LAB are often studied in complex laboratory media not containing these inhibitors, such as MRS and M17, where good growth is obtained [42] while similar growth may not be obtain on the industrial environment. It is also important to mention that cultures in the laboratory are cultivated in small quantity while the industry grow the culture in a bulky starter media [98]. Thus, CDM is used to study and optimize the growth and metabolic activity of LAB. Upon optimization of an enzymatic activity with a high control coefficient, modeling system can be used to study the effect of the enzyme in the industrial environment. Therefore, larger increase in the importance of bioengineering has been noticed in the areas of LAB applications. However, there is still a gap between laboratory research and industrial application that need to be given more attention.

\subsection{Decrease in Viability and Functionality during Storage}

Viability and functionality of LAB are a major concern especially when it comes to probiotic applications. While not all LAB strains are probiotics [99] most probiotic strains are belonging to LAB or bifidobacteria. Probiotics have shown to die in the food products duringrefrigeration distribution and storage [100,101]. Thus, several studies were carried out to enhance the probiotic viability and functionality during storage. With that aim, raffinose [102], fructooligosaccharides, mannitol, maltodextrin and pectin [103], inulin [104] and other ingredients were tested. In another studies, encapsulation or microcapsulation were used to protect the bacterial cells from the damage caused by the external environment and to maintain the viability [105]. In food fermentation, the nature of fermented food such as composition (nutrients and antimicrobials), structure (oxygen permeability and water activity) and $\mathrm{pH}$ value may affect the functionality of starter culture [1]. Interactions between different strains of LAB during fermentation process or storage may also influence the viability and functionality of LAB. For example, beverages with low $\mathrm{pH}$ values, below 4.4, combined with long storage periods could cause damage to LAB. Other limitations and challenges such as strain selection, inoculation level, growth and survival during processing, were discussed somewhere else in more details [106]. However, viability and functionality of LAB during processing, distribution, and storage need to be given more attention in research.

\subsection{Sweet Potato Base Medium: An Alternative}

In order to solve some of the negative characteristics of the existing media, a new media might be required. Recent work in our laboratory has used sweet potatoes (Ipomoea batatas) to develop a medium for LAB [65]. North Carolina is the leading state in sweet potato production, producing about $47.5 \%$ of the total production in the United States. Sweet potatoes are a rich source of carbohydrates (mainly starch and sugars), some amino acids, vitamins (vitamin $\mathrm{A}$, vitamin $\mathrm{C}$, thiamin (B1), riboflavin (B2), niacin, and vitamin E), minerals (calcium, iron, magnesium, phosphorus, potassium, sodium, and zinc), and dietary fiber $[107,108]$. Sweet potatoes also contain other minor nutrients such as antioxidants, triglycerides, linoleic acid, and palmitic acid [107,108]. Sweet potatoes also contribute to many health benefits including cardiovascular health, controlling blood sugar, and 
lowering glycemic score [107]. This nutritional tuber with a low production cost was used as an alternative to partially replace the expensive ingredients in LAB media in order to lower the cost and better meet with industrial requirements. Notice that this medium is formed based on sweet potato, agriculture product that been used as food and feed, the medium will better match with the industrial fermentation environment compared to other media such as MRS.

To form a sweet potato base medium (SPM), fresh sweet potatoes were baked in a conventional oven at $400^{\circ} \mathrm{C}$ for $1 \mathrm{~h}$. Baked sweet potatoes $(450 \mathrm{~g})$ were blended with deionized distilled water $(900.0 \mathrm{~mL})$, centrifuged, and supernatant was collected. SPM as finally composed contain: proteose peptone \# 3 (4.0 g), beef extract $(4.0 \mathrm{~g})$, yeast extract $(4.0 \mathrm{~g})$, sodium acetate $\mathrm{CH}_{3} \mathrm{COONa}(5.0 \mathrm{~g})$, Tween $80(1.0 \mathrm{~mL})$, disodium phosphate $\mathrm{Na}_{2} \mathrm{HPO}_{4}(2.0$ g), potassium phosphate $\mathrm{KH}_{2} \mathrm{PO}_{4}(2.0 \mathrm{~g})$, ammonium citrate $\mathrm{NH}_{4} \mathrm{C}_{6} \mathrm{H}_{5} \mathrm{O}_{7}(2.0 \mathrm{~g})$, magnesium sulfate

$\mathrm{MgSO}_{4} \cdot 7 \mathrm{H}_{2} \mathrm{O}(0.1 \mathrm{~g})$, manganese sulfate $\mathrm{MnSO}_{4} \cdot 5 \mathrm{H}_{2} \mathrm{O}$ $(0.05 \mathrm{~g})$, and L-Cysteine $(1 \mathrm{~g})$ for $1 \mathrm{~L}$ of supernatant. For evaluating SPM, ten strains of LAB wereindividually tested and the growth of LAB strains in SPM was compared to that in MRS. Turbidity (optical density at 610 $\mathrm{nm})$, bacterial population $(\log \mathrm{CFU} / \mathrm{mL})$, and $\mathrm{pH}$ values were used to evaluate the growth of LAB strains in SPM. Theresults showed no significant $(p>0.05)$ differences between MRS and SPM supporting the growth of tested strains (Figure 1). Further step was taken to evaluate the enzymatic activity of LAB in SPM compared to MRS. In summary, LAB strains growing in SPM showed better enzymatic activity compared to MRS. The use of sweet potato as basic component to form the medium will not only lower the cost, but it will enhance the medium with different sugars, several vitamins and minerals. In addition, this SPM may provide a growth environment that much similar to the industrial environment by using an agricultural product that is normally used in human food and animal feed. Please refer to Hayek [65] for more information in regard to SPM.

\section{Conclusion}

The fast growing characteristics of LAB and their metabolic activity have been employed in many applications in food production, agricultural industry, and probiotics. Since LAB are not naturally optimized for maximal production rates of biotechnologically important compounds, it is important to optimize, select, stabilize, and/or enhance the metabolic processes with regard to desired end products. To maximize the enzymatic activities of LAB it is thus important to optimize and control both biochemical and biophysical conditions. While the biochemical conditions are most likely established, controlling and optimizing biochemical conditions have many limitations and challenges. Biochemical conditions including stimulatory, preferred, and essential nutrients have significant impact on the growth and metabolic activity of LAB.

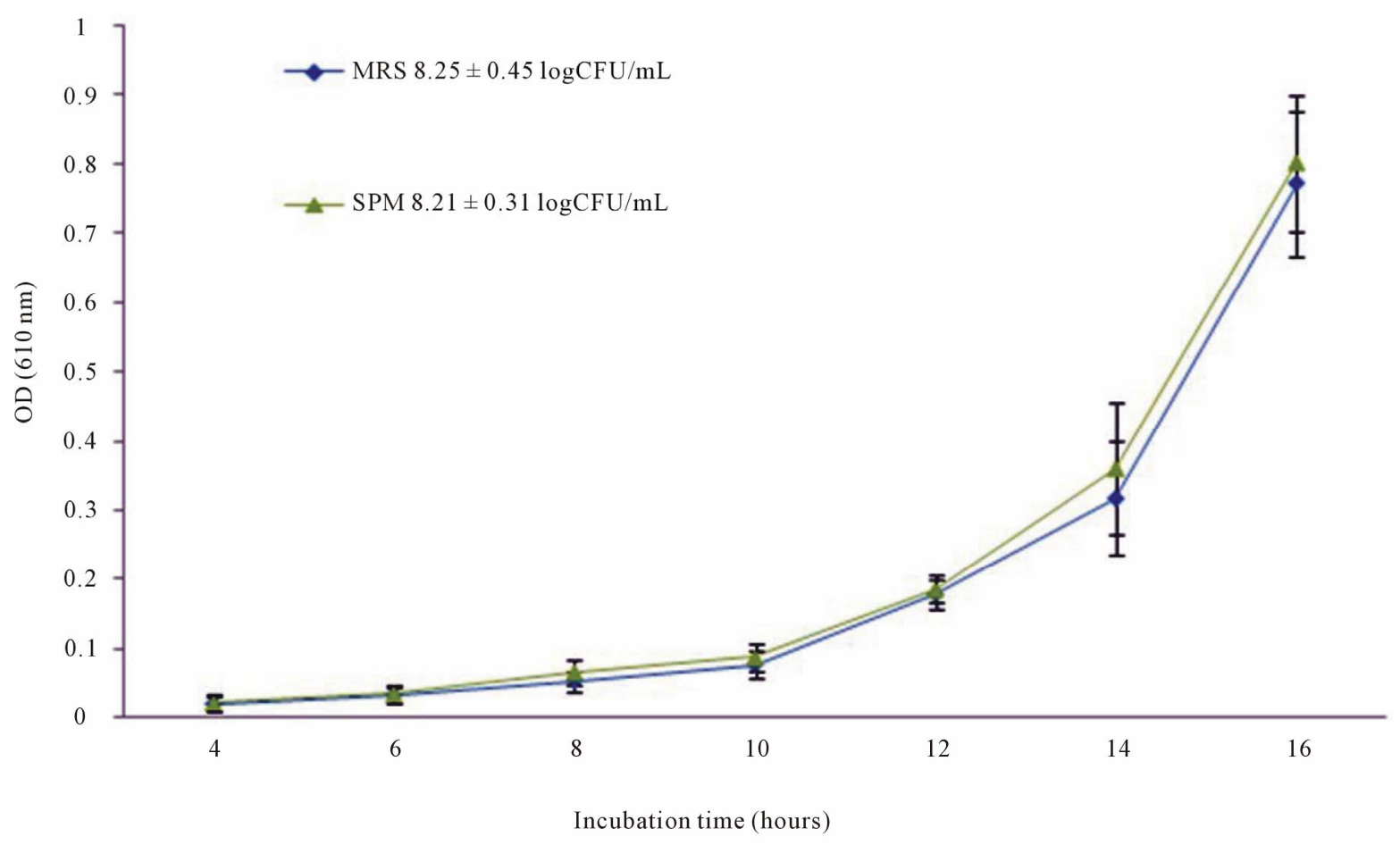

Figure 1. Average growth curves for ten tested LAB strains in MRS and SPM with average final bacterial population at $16 \mathrm{~h}$. Data points are the average of 3 replicates for ten tested strains with standard error. 
However, only a few nutritional parameters could be controlled at a time while holding other parameters constant. The nutritional parameters may also interact with each other resulting in faulty results. In addition, the fastidious characteristic of LAB, the ability of LAB strains to produce acid and antimicrobial compounds, and the variations in nutritional requirements among LAB strains may introduce additional limitations and challenges. Forming a culture medium that can deal with all or even most of the parameters and limitations continues to be a challenge. Accordingly, CDM were suggested in many studies as an alternative to deal with different limitations and challenges. CDM remain important to study LAB, when it is necessary to consider all possible substrates and control available energy, carbon, and nitrogen sources that might influence growth and metabolism. However, the industrial applications of LAB are not taken place in CDM and thus results from CDM may not be successful when applied in the industry. Since laboratory conditions are different from those found in the industrial environment, laboratory results may face different obstacles when it comes to industrial applications. Therefore, optimal fermentation control that leads to improved production of some metabolites and metabolic engineering that could focus on the steering of the metabolic flux in a well defined direction needs to be given more attention on research for better matching the industrial environment.

\section{Acknowledgements}

This work was supported by USDA National Institute of Food and Agriculture, Hatch project number NC.X-2345-09-170-1 in the Agricultural Research Program at North Carolina Agricultural and Technical State University.

\section{REFERENCES}

[1] D. Song, S. Ibrahim and S. Hayek, "Recent Application of Probiotics in Food and Agricultural Science," In: E. C. Rigobelo, Ed., Probiotics, InTech, Manhattan, 2012, pp. 1-34. http://dx.doi.org/10.5772/50121

[2] H. Rodríguez, J. A. Curiel, J. M. Landete, B. de las Rivas, F. L. de Felipe, C. Gómez-Cordovés, J. M. Mancheño and R. Muñoz, "Food Phenolics and Lactic Acid Bacteria," International Journal of Food Microbiology, Vol. 132, No. 2-3, 2009, pp. 79-90. http://dx.doi.org/10.1016/j.ijfoodmicro.2009.03.025

[3] L. Morelli, M. L. Calleagri, F. K. Vogensen and A. Von Wright, "Genetics of Lactic Acid Bacteria," In: S. Lahtinne, S. Salminen, A. Von Wright and A. Ouwehand, Eds., Lactic Acid Bacteria: Microbiological and Functional Aspects, CRC Press, London, 2011, pp. 18-33. http://dx.doi.org/10.1201/b11503-3

[4] A. Von Wright and L. Axelsson, "Lactic Acid Bacteria: An Introduction," In: S. Lahtinne, S. Salminen, A. Von
Wright and A. Ouwehand, Eds., Lactic Acid Bacteria: Microbiological and Functional Aspects, CRC Press, London, 2011, pp. 1-17. http://dx.doi.org/10.1201/b11503

[5] E. Vera Pingitore, E. M. Hebert, F. Sesma and M. E. Nader-Macias, "Influence of Vitamins and Osmolites on Growth and Bacteriocin Production by Lactobacillus salivarius CRL 1328 in a Chemically Defined Medium," Canadian Journal of Microbiology, Vol. 55, No. 3, 2009, pp. 304-310. http://dx.doi.org/10.1139/W08-092

[6] E. M. Hébert, R. R. Raya and G. S. de Giori, "Evaluation of Minimal Nutritional Requirements of Lactic Acid Bacteria Used in Functional Foods," In: J. M. Walker, J. F. Spencer and A. L. Ragout de Spencer, Eds., Methods in Biotechnology, Humana Press, Totowa, 2004, pp. 139150.

[7] C. Letort and V. Juillard, "Development of a Minimal Chemically Defined Medium for the Exponential Growth of Streptococcus thermophilus," Journal of Applied Microbiology, Vol. 91, No. 6, 2001, pp. 1023-1029. http://dx.doi.org/10.1046/j.1365-2672.2001.01469.x

[8] S. Tripuraneni, "Effect of Nutrient Supplements on $\mathrm{Cu}-$ cumber Fermentation by Lactic Acid Bacteria," MS Research, University College of Technology, Osmania University, Ann Arbor, 2008.

[9] F. Bringel, "Carbamoylphosphate and Natural Auxotrophies in Lactic Acid Bacteria," Le Lait, Vol. 78, No. 1, 1998, pp. 31-37. http://dx.doi.org/10.1051/lait:199815

[10] S. Sanchez and A. L. Demain, "Metabolic Regulation and Overproduction of Primary Metabolites," Microbialogy and Biotechnology, Vol. 1, No. 4, 2008, pp. 283-319. http://dx.doi.org/10.1111/j.1751-7915.2007.00015.x

[11] M. H. N. Hoefnagel, M. J. C. Starrenburg, D. E. Martens, J. Hugenholtz, M. Kleerebezem, I. I. V. Swam, R. Bongers, H. V. Westerhoff and J. L. Snoep, "Metabolic Engineering of Lactic Acid Bacteria, the Combined Approach: Kinetic Modelling, Metabolic Control and Experimental Analysis," Microbiology, Vol. 148, 2002, pp. 1003-1013.

[12] N. Kirilov, T. Petkova, J. Atanasova, S. Danova, I. Iliev, Y. Popov, T. Haertle and I. Ivanova, "Proteolytic Activity in Lactic Acid Bacteria from Iraq, Armenia and Bulgaria," Biotechnology \& Biotechnological Equipment, Vol. 23, 2009, pp. 643-646.

[13] K. Savijoki, H. Ingmer and P. Varmanen, "Proteolytic Systems of Lactic Acid Bacteria," Applied Microbiology and Biotechnology, Vol. 71, No. 4, 2006, pp. 394-406. http://dx.doi.org/10.1007/s00253-006-0427-1

[14] H. König and J. Fröhlich, "Lactic Acid Bacteria," In: H. König, G. Unden and J. Fröhlich, Eds., Biology of Microorganisms on Grapes, in Must and in Wine, Springer, Verlag, Berlin Heidelberg, 2009, pp. 3-29. http://dx.doi.org/10.1007/978-3-540-85463-0_1

[15] L. Axelsson, "Lactic Acid Bacteria: Classification and Physiology," In: S. Salminen, A. von Wright and A. C. Ouwehand, Eds., Lactic Acid Bacteria: Microbiology and Functional Aspects, Marcel Dekker, New York, 2004, pp. 1-66. http://dx.doi.org/10.1201/9780824752033.ch1

[16] O. Kandler, "Carbohydrate Metabolism in Lactic Acid 
Bacteria," Antonie Van Leeuwenhoek, Vol. 49, No. 3, 1983, pp. 209-224.

http://dx.doi.org/10.1007/BF00399499

[17] R. P. John, K. M. Nampoothiri and A. Pandey, "Fermentative Production of Lactic Acid from Biomass: An Overview on Process Developments and Future Perspectives," Applied Microbiology and Biotechnology, Vol. 74, No. 3, 2007, pp. 524-534.

http://dx.doi.org/10.1007/s00253-006-0779-6

[18] T. Bintsis, A. Vafopoulou-Mastrojiannaki, E. LitopoulouTzanetaki and R. K. Robinson, "Protease, Peptidase and Esterase Activities by Lactobacilli and Yeast Isolates from Feta Cheese Brine," Journal of Applied Microbiology, Vol. 95, No. 1, 2003, pp. 68-77. http://dx.doi.org/10.1046/j.1365-2672.2003.01980.x

[19] M. Liu, J. R. Bayjanov, B. Renckens, A. Nauta and R. J. Siezen, "The Proteolytic System of Lactic Acid Bacteria Revisited: A Genomic Comparison," BMC Genomics, Vol. 11, 2010, pp. 1-15.

[20] Q. Yuan and G. T. Furuta, "Insights into Milk Protein Allergy: Microenvironment Matters," Gastroenterol, Vol. 124, No. 1, 2003, pp. 259-261. http://dx.doi.org/10.1053/gast.2003.1240259

[21] M. Liu, A. Nauta, C. Francke and R. J. Siezen, "Comparative Genomics of Enzymes in Flavor-Forming Pathways from Amino Acids in Lactic Acid Bacteria," Applied and Environmental Microbiology, Vol. 74, No. 15, 2008, pp. 4590-4600. http://dx.doi.org/10.1128/AEM.00150-08

[22] M. K. Doeven, J. Kok and B. Poolman, "Specificity and Selectivity Determinants of Peptide Transport in Lactococcus lactis and Other Microorganisms," Molecular Microbiology, Vol. 57, 2005, pp. 640-649.

http://dx.doi.org/10.1111/j.1365-2958.2005.04698.x

[23] S. A. Meyers, S. L. Cuppett and R. W. Hutkins, "Lipase Production by Lactic Acid Bacteria and Activity on Butter Oil," Food Microbiology, Vol. 13, No. 5, 1996, pp. 383-389. http://dx.doi.org/10.1006/fmic.1996.0044

[24] M. Katz, R. Medina, S. Gonzalez and G. Oliver, "Esterolytic and Lipolytic Activities of Lactic Acid Bacteria Isolated from Ewes Milk and Cheese," Journal of Food Protection, Vol. 65, 2002, pp. 1997-2001.

[25] J. Ogawa, S. Kishino, A. Ando, S. Sugimoto, K. Mihara and S. Shimizu, "Production of Conjugated Fatty Acids by Lactic Acid Bacteria," Journal of Bioscience and Bioengineering, Vol. 100, No. 4, 2005, pp. 355-364. http://dx.doi.org/10.1263/jbb.100.355

[26] M. P. Taranto, M. Medici, G. Perdigon, A. P. Ruiz Holgado and G. F. Valdez, "Evidence for Hypocholesterolemic Effect of Lactobacillus reuteri in Hypercholesterolemic Mice," Journal of Dairy Science, Vol. 81, No. 9, 1998, pp. 2336-2340. http://dx.doi.org/10.3168/jds.S0022-0302(98)70123-7

[27] H. Chen, S. Hayek, J. R. Guzman, N. D. Gillitt, S. A. Ibrahim, C. Jobin and S. Sang, "The Microbiota Is Essential for the Generation of Black Tea Theaflavins-Derived Metabolites," PloS One, Vol. 7, No. 12, 2012, Article ID: e51001. http://dx.doi.org/10.1371/journal.pone.0051001
[28] L. M. Cintas, M. P. Casaus, C. Herranz, I. F. Nes and P. E. Hernández, "Review: Bacteriocins of Lactic Acid Bacteria," Food Science and Technology International, Vol. 7, 2001, pp. 281-305.

[29] A. Lonvaud-Funel, "Lactic Acid Bacteria in the Quality Improvement and Depreciation of Wine," Antonie van Leeuwenhoek, Vol. 76, No. 1-4, 1999, pp. 317-331. http://dx.doi.org/10.1023/A:1002088931106

[30] D. Jussier, A. D. Morneau and R. M. de Orduña, "Effect of Simultaneous Inoculation with Yeast and Bacteria on Fermentation Kinetics and Key Wine Parameters of Cool-Climate Chardonnay," Applied and Environmental Microbiology, Vol. 72, No. 1, 2006, pp. 221-227. http://dx.doi.org/10.1128/AEM.72.1.221-227.2006

[31] A. D. Welman and I. S. Maddox, "Exopolysaccharides from Lactic Acid Bacteria: Perspectives and Challenges," Trends in Biotechnology, Vol. 21, No. 6, 2003, pp. 269274. http://dx.doi.org/10.1016/S0167-7799(03)00107-0

[32] S. Petry, S. Furlan, M. J. Crepeau, J. Cerning and M. Desmazeaud, "Factors Affecting Exocellular Polysaccharide Production by Lactobacillus delbrueckii subsp. Bulgaricus Grown in a Chemically Defined Medium," $A p$ plied and Environmental Microbiology, Vol. 66, No. 8, 2000, pp. 3427-3431.

http://dx.doi.org/10.1128/AEM.66.8.3427-3431.2000

[33] T. Lechiancole, A. Ricciardi and E. Parente, "Optimization of Media and Fermentation Conditions for the Growth of Lactobacillus sakei," Annals of Microbiology, Vol. 52, 2002, pp. 257-274.

[34] E. M. Hébert, R. R. Raya and G. S. Giori, "Nutritional Requirements of Lactobacillusdelbrueckii subsp. lactis in a Chemically Defined Medium," Currunt Microbiology, Vol. 49, No. 5, 2004, pp. 341-345. http://dx.doi.org/10.1007/s00284-004-4357-9

[35] C. Foucaud, A. Francois and J. Richard, "Development of a Chemically Defined Medium for the Growth of Leuconostoc mesenteroides," Applied and Environmental Microbiology, Vol. 63, 1997, pp. 301-304.

[36] F. Leroy, J. Verluyten and L. De Vuyst, "Functional Meat Starter Cultures for Improved Sausage Fermentation," International Journal of Food Microbiology, Vol. 106, No. 3, 2006, pp. 270-285.

[37] L. de Vuyst and E. J. Vandamme, "Influence of the Carbon Source on Nisin Production in Lactococcus lactis subsp. lactis Batch Fermentations," Journal of General Microbiology, Vol. 138, No. 3, 1992, pp. 571-578. http://dx.doi.org/10.1099/00221287-138-3-571

[38] L. D. Vuyst, G. Falony and F. Leroy, "Probiotics in Fermented Sausages," Meat Science, Vol. 80, No. 1, 2008, pp. 75-78. http://dx.doi.org/10.1016/j.meatsci.2008.05.038

[39] M. M. O' Donnell, B. M. Forde, B. Neville, P. R. Ross and P. W. O' Toole, 'Carbohydrate Catabolic Flexibility in the Mammalian Intestinal Commensal Lactobacillus ruminis Revealed by Fermentation Studies Aligned to Genome Annotations," Microbial Cell Factories, Vol. 10, Suppl. 1, 2011, pp. 1-11. http://dx.doi.org/10.1186/1475-2859-10-S1-S12

[40] J. H. Kim, S. P. Shoemaker and D. A. Mills, "Relaxed Control of Sugar Utilization in Lactobacillus brevis," Microbi- 
ology, Vol. 155, No. 4, 2009, pp. 1351-1359. http://dx.doi.org/10.1099/mic.0.024653-0

[41] M. Calderon, G. Loiseau and J. P. Guyot, "Nutritional Requirements and Simplified Cultivation Medium to Study Growth and Energetics of a Sourdough Lactic Acid Bacterium Lactobacillus fermentum Ogi E1 During Heterolactic Fermentation of Starch," Journal of Applied Microbiology, Vol. 90, No. 4, 2001, pp. 508-516. http://dx.doi.org/10.1046/j.1365-2672.2001.01272.x

[42] N. Terrade, R. Noël, R. Couillaud and R. M. de Orduña, "A New Chemically Defined Medium for Wine Lactic Acid Bacteria," Food Research International, Vol. 42, No. 3, 2009, pp. 363-367. http://dx.doi.org/10.1016/j.foodres.2008.12.011

[43] B. Degeest, F. Vaningelgem and L. de Vuyst, "Microbial Physiology, Fermentation Kinetics, and Process Engineering of Heteropolysaccharide Production by Lactic Acid Bacteria," International Dairy Journal, Vol. 11, No. 9, 2001, pp. 747-757. http://dx.doi.org/10.1016/S0958-6946(01)00118-2

[44] R. Tabasco, T. Paarup, C. Janer, C. Pelįez and T. Requena, "Selective Enumeration and Identification of Mixed Cultures of Streptococcus thermophilus, Lactobacillus delbrueckii subsp. bulgaricus, L. acidophilus, L. paracasei subsp. paracasei and Bifidobacterium lactis in Fermented Milk," International Dairy Journal, Vol. 17, No. 9, 2007, pp. 1107-1114. http://dx.doi.org/10.1016/j.idairyj.2007.01.010

[45] R. I. Dave and N. P. Shah, "Evaluation of Media for Selective Enumeration of Streptococcus thermophilus, Lactobacillus delbrueckii ssp. bulgaricus, Lactobacillus acidophilusi, and Bifidobacteria," Journal of Dairy Science, Vol. 79, No. 9, 1996, pp. 1529-1536. http://dx.doi.org/10.3168/jds.S0022-0302(96)76513-X

[46] M. Haros, M. Bielecka, J. Honke and Y. Sanz, "PhytateDegrading Activity in Lactic Acid Bacteria," Polish Journal of Food and Nutrition Sciences, Vol. 58, No. 1, 2008, pp. 33-40.

[47] R. Barrangou, S. J. Lahtinen, F. Ibrahim and A. C. Ouwehand, "Genus Lactobacilli," In: S. Lahtinne, S. Salminen, A. Von Wright and A. Ouwehand, Eds., Lactic Acid Bacteria: Microbiological and Functional Aspects, CRC Press, London, 2011, pp. 77-92. http://dx.doi.org/10.1201/b11503-6

[48] T. Møretrø, B. F. Hagen and L. Axelsson, "A New, Completely Defined Medium for Meat Lactobacilli," Journal of Applied Microbiology, Vol. 85, No. 4, 1998, pp. 715-722.

[49] Y. Sawatari, T. Hirano and A. Yokota, "Development of Food Grade Media for the Preparation of Lactobacillus plantarum Starter Culture," The Journal of General and Applied Microbiology, Vol. 52, No. 6, 2006, pp. 349-356. http://dx.doi.org/10.2323/igam.52.349

[50] J. Boekhorst, R. J. Siezen, M. C. Zwahlen, D. Vilanova, R. D. Pridmore, A. Mercenier, M. Kleerebezem, W. M. de Vos, H. Brüssow and F. Desiere, "The Complete Genomes of Lactobacillus plantarum and Lactobacillus johnsonii Reveal Extensive Differences in Chromosome Organization and Gene Content," Microbiology, Vol. 150, No. 11, 2004, pp. 3601-3611. http://dx.doi.org/10.1099/mic.0.27392-0

[51] L. Yu, T. Lei, X. Ren, X. Pei and Y. Feng, "Response Surface Optimization of L-(+)-Lactic Acid Production Using corn steep liquor as an Alternative Nitrogen Source by Lactobacillus rhamnosus CGMCC 1466," Biochemical Engineering Journal, Vol. 39, No. 3, 2008, pp. 496502. http://dx.doi.org/10.1016/j.bej.2007.11.008

[52] L. Aguirre, M. S. Garro and G. Savoy de Giori, "Enzymatic Hydrolysis of Soybean Protein Using Lactic Acid Bacteria," Food Chemistry, Vol. 111, No. 4, 2008, pp. 976-982. http://dx.doi.org/10.1016/j.foodchem.2008.05.018

[53] J. A. Vazquez, M. P. Gonzalez and M. A. Murado, "Peptones from Autohydrolysed Fish Viscera for Nisin and Pediocin Production," Journal of Biotechnology, Vol. 112, No. 3, 2004, pp. 299-311. http://dx.doi.org/10.1016/j.jbiotec.2004.04.011

[54] I. M. Aasen, T. Møretrø, T. Katla, L. Axelsson and I. Storrø, "Influence of Complex Nutrients, Temperature and $\mathrm{pH}$ on Bacteriocin Production by Lactobacillus sakei CCUG 42687," Applied Microbiology and Biotechnology, Vol. 53, No. 2, 2000, pp. 159-166. http://dx.doi.org/10.1007/s002530050003

[55] S. Oh, S. Rheem, J. Sim, S. Kim and Y. Baek, "Optimizing Conditions for the Growth of Lactobacillus casei YIT 9018 in Tryptone-Yeast Extract-Glucose Medium by Using Response Surface Methodology," Applied and Environmental Microbiology, Vol. 61, No. 11, 1995, pp. 3809-3814.

[56] A. P. Desbois and V. J. Smith, "Antibacterial Free Fatty acids: Activities, Mechanisms of Action and Biotechnological Potential," Applied Microbiology and Biotechnology, Vol. 85, No. 6, 2010, pp. 1629-1642. http://dx.doi.org/10.1007/s00253-009-2355-3

[57] L. Partanen, N. Marttinen and T. Alatossava, "Fats and Fatty Acids as Growth Factors for Lactobacillus delbrueckii," Systematic and Applied Microbiology, Vol. 24, No. 4, 2001, pp. 500-506. http://dx.doi.org/10.1078/0723-2020-00078

[58] P. Kankaanpää, B. Yang, H. Kallio, E. Isolauri and S. Salminen, "Effects of Polyunsaturated Fatty Acids in Growth Medium on Lipid Composition and on Physicochemical Surface Properties of lactobacilli," Applied and Environmental Microbiology, Vol. 70, No. 1, 2004, pp. 129-136. http://dx.doi.org/10.1128/AEM.70.1.129-136.2004

[59] J. K. Jenkins and P. D. Courtney, "Lactobacillus Growth and Membrane Composition in the Presence of Linoleic or Conjugated Linoleic Acid," Canadian Journal of Microbiology, Vol. 49, No. 1, 2003, pp. 51-57.

[60] P. E. Kankaanpa, S. J. Salminen, E. Isolauri and Y. K. Lee, "The Influence of Polyunsaturated Fatty Acids on Probiotic Growth and Adhesion," FEMS Microbiology Letters, Vol. 194, No. 2, 2001, pp. 149-153.

[61] A. Wegkamp, B. Teusink, W. M. De Vos and E. J. Smid, "Development of a Minimal Growth Medium for Lactobacillus plantarum," Letters in Applied Microbiology, Vol. 50, No. 2010, pp. 57-64.

http://dx.doi.org/10.1111/j.1472-765X.2009.02752.x

[62] J. J. Fitzpatrick, M. Ahrens and S. Smith, "Effect of Man- 
ganese on Lactobacillus casei Fermentation to Produce Lactic Acid from Whey Permeate," Process Biochemistry, Vol. 36, No. 7, 2001, pp. 671-675. http://dx.doi.org/10.1016/S0032-9592(00)00265-X

[63] S. A. Ibrahim, A. Y. Alazzeh, S. S. Awaisheh, D. Song, A. Shahbazi and A. A. AbuGhazaleh, "Enhancement of $\alpha$ - and $\beta$-Galactosidase Activity in Lactobacillus reuteri by Different Metal Ions," Biological Trace Element Research, Vol. 136, No. 1, 2010, pp. 106-116.

http://dx.doi.org/10.1007/s12011-009-8519-2

[64] M. G. Macedo, C. Lacroix, N. J. Gardner and C. P. Champagne, "Effect of Medium Supplementation on Exopolysaccharide Production by Lactobacillus rhamnosus RW9595M in Whey Permeate," International Dairy Journal, Vol. 12, No. 5, 2002, pp. 419-426. http://dx.doi.org/10.1016/S0958-6946(01)00173-X

[65] S. A. Hayek, "Use of Sweet Potato to Develop a Medium for Cultivation of Lactic Acid Bacteria," Doctor of Philosophy Research Energy and Environmental Systems, North Carolina A\&T State University, Greensboro, NC, USA, 2013.

[66] W. Y. Jeng, N. C. Wang, M. H. Lin, C. T. Lin, Y. C. Liaw, W. J. Chang, C. I. Liu, P. H. Liang and A. H. J. Wang, "Structural and Functional Analysis of Three $\beta$-Glucosidases from Bacterium Clostridium cellulovorans, fungus Trichoderma reesei and Termite Neotermes koshunensis," Journal of Structural Biology, Vol. 173, No. 1, 2011, pp. 46-56. http://dx.doi.org/10.1016/j.jsb.2010.07.008

[67] S. Tham, C. Chang, H. Huang, Y. Lee, T. Huang and C. C. Chang, "Biochemical Characterization of an Acid Phosphatase from Thermus thermophilus," Bioscience, Biotechnology, and Biochemistry, Vol. 74, No. 4, 2010, pp. 727-735. http://dx.doi.org/10.1271/bbb.90773

[68] H. Aqel, "Effects of pH-Values, Temperatures, Sodium Chloride, Metal Ions, Sugars and Tweens on the Acid Phosphatase Activity by Thermophilic bacillus Strains," European Journal of Scientific Research, Vol. 75, No. 2, 2012, pp. 262-268.

[69] M. C. Palacios, M. Haros, C. M. Rosell and Y. Sanz, "Characterization of an Acid Phosphatase from Lactobacillus pentosus: Regulation and Biochemical Properties," Journal of Applied Microbiology, Vol. 98, No. 1, 2005, pp. 229-237.

[70] N. A. Chamoles, G. Niizawa, M. Blanco, D. Gaggioli and C. Casentini, "Glycogen Storage Disease Type II: Enzymatic Screening in Dried Blood Spots on Filter Paper," Clinica Chimica Acta, Vol. 347, No. 1-2, 2004, pp. 97102. http://dx.doi.org/10.1016/j.ccen.2004.04.009

[71] M. Zacharof, R. Lovitt and K. Ratanapongleka, "Optimization of Growth Conditions for Intensive Propagation, Growth Development and Lactic Acid Production of Selected Strains of Lactobacilli," Engineering Our Future: Are We up to the Challenge? Burswood Entertainment Complex, 27-30 September 2009, pp. 1830-1839.

[72] J. Y. Li, L. W. Zhang, M. Du, X. Han, H. X. Yi, C. F. Guo, Y. C. Zhang, X. Luo, Y. H. Zhang, Y. J. Shan and A. J. Hou, "Effect of Tween Series on Growth and cis-9, trans-11 Conjugated Linoleic Acid Production of Lactobacillus acidophilus F0221 in the Presence of Bile Salts,"
International Journal of Molecular Science, Vol. 12, No. 12, 2011, pp. 9138-9154.

http://dx.doi.org/10.3390/ijms12129138

[73] L. Bâati, C. Fabre-Gea, D. Auriol and P. J. Blanc, "Study of the Cryotolerance of Lactobacillus acidophilus: Effect of Culture and Freezing Conditions on the Viability and Cellular Protein Levels," International Journal of Food Microbiology, Vol. 59, No. 3, 2000, pp. 241-247. http://dx.doi.org/10.1016/S0168-1605(00)00361-5

[74] S. A. Ibrahim, S. A. Ahmed and D. Song, "Use of Tween 80 to Enhance Bile Tolerance of Lactobacillus reuteri," Milchwissenschaft, Vol. 64, No. 1, 2009, pp. 29-31.

[75] H. Kimoto, S. Ohmomo and T. Okamoto, "Enhancement of Bile Tolerance in Lactococci by Tween 80," Journal of Applied Microbiology, Vol. 92, No. 1, 2002, pp. 41-46. http://dx.doi.org/10.1046/j.1365-2672.2002.01505.x

[76] E. Parente and C. Hill, "A Comparison of Factors Affecting the Production of Two Bacteriocins from Lactic Acid Bacteria," Journal of Applied Bacteriology, Vol. 73, No. 4, 1992, pp. 290-298. http://dx.doi.org/10.1111/j.1365-2672.1992.tb04980.x

[77] A. L. Tang, G. Wilcox, K. Z. Walker, N. P. Shah, J. F. Ashton and L. Stojanovska, "Phytase Activity from Lactobacillus spp. in Calcium-Fortified Soymilk," Journal of Food Science, Vol. 75, No. 6, 2010, pp. M373-M376. http://dx.doi.org/10.1111/j.1750-3841.2010.01663.x

[78] A. Reale, L. Mannina, P. Tremonte, A. P. Sobolev, M. Succi and E. Sorrentino, et al., "Phytate Degradation by Lactic Acid Bacteria and Yeasts During the Wholemeal Dough Fermentation: A ${ }^{31}$ P NMR Study," Journal of Agricultural and Food Chemistry, Vol. 52, No. 20, 2004, pp. 6300-6305. http://dx.doi.org/10.1021/jf049551p

[79] K. Y. Chan and K. B. Li, "Production and Properties of Alpha-Glucosidase from Lactobacillus acidophilus," Applied and Environmental Microbiology, Vol. 46, No. 6, 1983, pp. 1380-1387.

[80] P. M. Mahajan, K. M. Desai and S. S. Lele, "Production of Cell Membrane-Bound $\alpha$ - and $\beta$-Glucosidase by Lactobacillus acidophilus," Food and Bioprocess Technology, Vol. 5, No. 2, 2012, pp. 706-718. http://dx.doi.org/10.1007/s11947-010-0417-2

[81] R. Akuzawa and P. F. Fox, “Acid Phosphatase in Cheese,” Animal Science Journal, Vol. 75, No. 5, 2004, pp. 385-391. http://dx.doi.org/10.1111/j.1740-0929.2004.00202.x

[82] M. D. Altaf, B. J. Naveena and G. Reddy, "Use of Inexpensive Nitrogen Sources and Starch for L $(+)$ Lactic Acid Production in Anaerobic Submerged Fermentation," Bioresource Technology, Vol. 98, No. 3, 2007, pp. 498-503. http://dx.doi.org/10.1016/j.biortech.2006.02.013

[83] B. Djeghri-Hocine, M. Boukhemis, M. N. Zidoune and A. Amrane, "Evaluation of De-Lipidated Egg Yolk and Yeast Autolysate as Growth Supplements for Lactic Acid Bacteria Culture," International Journal of Dairy Technology, Vol. 60, No. 4, 2007, pp. 292-296. http://dx.doi.org/10.1111/j.1471-0307.2007.00351.x

[84] H. Gaudreau, N. Renard, C. P. Champagne and D. Van Horn, "The Evaluation of Mixtures of Yeast and Potato Extracts in Growth Media for Biomass Production of Lactic Cultures," Canadian Journal of Microbiology, Vol. 
48, No. 7, 2002, pp. 626-634. http://dx.doi.org/10.1139/w02-052

[85] P. Burns, G. Vinderola, F. Molinari and J. Reinheimer, "Suitability of Whey and Buttermilk for the Growth and Frozen Storage of Probiotic Lactobacilli," International Journal of Dairy Technology, Vol. 61, No. 2, 2008, pp. 156-164. http://dx.doi.org/10.1111/j.1471-0307.2008.00393.x

[86] M. Ziadi, F. Rezouga, H. Bouallagui, L. Baâti, N. Ben Othman, P. Thonart and M. Hamdi, "Kinetic Study of Lactococcus lactis strains (SLT6 and SLT10) Growth on PapainHydrolysed Whey," World Journal of Microbiology and Biotechnology, Vol. 26, No. 12, 2010, pp. 2223-2230. http://dx.doi.org/10.1007/s11274-010-0407-6

[87] R. P. John, K. M. Nampoothiri and A. Pandey, "SolidState Fermentation for L-lactic acid Production from Agro Wastes Using Lactobacillus delbrueckii," Process Biochemistry, Vol. 41, No. 4, 2006, pp. 759-763. http://dx.doi.org/10.1016/j.procbio.2005.09.013

[88] E. B. Kurbanoglu, "Enhancement of Lactic Acid Production with Ram Horn Peptone by Lactobacillus casei," World Journal of Microbiology and Biotechnology, Vol. 20, No. 1, 2004, pp. 37-42. http://dx.doi.org/10.1023/B:WIBI.0000013289.89034.47

[89] F. Leroy and L. De Vuyst, "Growth of the BacteriocinProducing Lactobacillus sakei Strain CTC 494 in MRS Broth Is Strongly Reduced Due to Nutrient Exhaustion: A Nutrient Depletion Model for the Growth of Lactic Acid Bacteria," Applied and Environmental Microbiology, Vol. 67, No. 10, 2001, pp. 4407-4413. http://dx.doi.org/10.1128/AEM.67.10.4407-4413.2001

[90] P. Raghavendra and P. M. Halami, "Screening, Selection and Characterization of Phytic Acid Degrading Lactic Acid Bacteria from Chicken Intestine," International Journal of Food Microbiology, Vol. 133, No. 1-2, 2009, pp. 129134. http://dx.doi.org/10.1016/j.ijfoodmicro.2009.05.006

[91] M. C. Palaciosa, M. Harosa, Y. Sanzb and C. M. Rosella, "Selection of Lactic Acid Bacteria with High Phytate Degrading Activity for Application in Whole Wheat Breadmaking," LWT-Food Science and Technology, Vol. 41, No. 1, 2008, pp. 82-92.

[92] G. Zhang, D. A. Mills and D. E. Block, "Development of Chemically Defined Media Supporting High-Cell-Density Growth of Lactococci, Enterococci, and Streptococci," Applied and Environmental Microbiology, Vol. 75, No. 4, 2009, pp. 1080-1087. http://dx.doi.org/10.1128/AEM.01416-08

[93] R. Hartemink, V. R. Domenech and F. M. Rombouts, "LAMVAB-A New Selective Medium for the Isolation of Lactobacilli from Faeces," Journal of Microbiological Methods, Vol. 29, No. 2, 1997, pp. 77-84. http://dx.doi.org/10.1016/S0167-7012(97)00025-0

[94] N. Terrade and R. Mira de Orduña, "Determination of the Essential Nutrient Requirements of Wine-Related Bacteria from the Genera Oenococcus and Lactobacillus," International Journal of Food Microbiology, Vol. 133, No. $1-2,2009$, pp. 8-13.

http://dx.doi.org/10.1016/j.ijfoodmicro.2009.03.020

[95] E. A. Pfeiler and T. R. Klaenhammer, "The Genomics of Lactic Acid Bacteria," Trends in Microbiology, Vol. 15,
No. 2, 2007, pp. 546-553.

http://dx.doi.org/10.1016/j.tim.2007.09.010

[96] E. Coton, S. Torlois, A. Bertrand and A. LonvaudFunel, "Amines Biogènes et Bactéries Lactiques Du Vin," Bulletin de l'OIV, Vol. 72, 1999, pp. 22-35.

[97] R. Mira de Orduña, S. Q. Liu, M. L. Patchett and G. J. Pilone, "Ethyl Carbamate Precursor Citrulline Formation from Arginine Degradation by Malolactic Wine Lactic Acid Bacteria," FEMS Microbiology Letters, Vol. 183, No. 1, 2000, pp. 31-35.

[98] S. A. Ibrahim and M. H. Daguri, "Bulk Starter Media for Mesophilic Starter Cultures: A Review," Food and Environmental Sanitation, Vol. 16, No. 12, 1996, pp. 823-828.

[99] V. Azaïs-Braesco, J. L. Bresson, F. Guarner and G. Corthier, "Not All Lactic Acid Bacteria are Probiotics, ...but Some are," British Journal of Nutrition, Vol. 103, No. 7, 2010, pp. 1079-1081. http://dx.doi.org/10.1017/S0007114510000723

[100] N. P. Shah, "Functional Cultures and Health Benefits," International Dairy Journal, Vol. 17, No. 11, 2007, pp. 12621277. http://dx.doi.org/10.1016/j.idairyj.2007.01.014

[101] K. Kailasapathy and J. Chin, "Survival and Therapeutic Potential of Probiotic Organisms with Reference to Lactobacillus acidophilus and Bifidibacerium spp.," Immunology and Cell Biology, Vol. 78, No. 1, 2000, pp. 80-88. http://dx.doi.org/10.1046/j.1440-1711.2000.00886.x

[102] C. Martinez-Villaluenga, J. Frías, R. Gómez and C. Vidal-Valverde, "Influence of Addition of Raffinose Family Oligosaccharides on Probiotic Survival in Fermented Milk During Refrigerated Storage," International Dairy Journal, Vol. 16, No. 7, 2006, pp. 768-774. http://dx.doi.org/10.1016/j.idairyj.2005.08.002

[103] S. K. Yeo and M. T. Liong, "Effect of Prebiotics on Viability and Growth Characteristics of Probiotics in Soymilk," Journal of the Science of Food and Agriculture, Vol. 90, No. 2, 2010, pp. 267-275. http://dx.doi.org/10.1002/jsfa.3808

[104] D. Rodrigues, T. A. P. Rocha-Santos, C. I. Pereira, A. M. Gomes, F. X. Malcata and A. C. Freitas, "The Potential Effect of FOS and Inulin upon Probiotic Bacterium Performancein Curdled Milk Matrices," LWT-Food Science and Technology, Vol. 44, 2011, pp. 100-108.

[105] M. Del Piano, L. Morelli, G. Strozzi, S. Allesina, M. Barba, F. Deidda, P. Lorenzini, M. Ballare, F. Montino, M. Orsello, M. Sartoria, E. Garelloa, S. Carmagnolaa, M. Pagliaruloa and L. Capursod, "Probiotics: From Research to Consumer," Digestive and Liver Disease, Vol. 38, Suppl. 2, 2006, pp. S248-S255. http://dx.doi.org/10.1016/S1590-8658(07)60004-8

[106] C. P. Champagne, "19 Some Technological Challenges in the Addition of Probiotic Bacteria to Foods," Springer Science + Business Media, New York, 2009, pp. 761-804.

[107] K. Broihier, "Sweet Potato: Tuber Delivers Top-Notch Nutrition," Environmental Nutrition, Vol. 29, No. 10, 2006, p. 8.

[108] G. Padmaja, "Uses and Nutritional Data of Sweetpotato," In: G. Loebenstein and G. Thottappilly, Eds., The Sweetpotato, Springer, Belgium, 2009, pp. 189-234. 